Revista Iberoamericana, Vol. LXXIII, Núm. 220, Julio-Septiembre 2007, 563-579

\title{
LOCALIZACIÓN DEL PODER EN EL PERÚ: REFLEXIONES EN TORNO A LA REPRESENTACIÓN DE LA INDIGENIDAD Y FEMINEIDAD EN TRES NOVELAS PERUANAS
}

POR

\author{
Linda L. GRABner-Coronel \\ Canisius College
}

Hace más de cien años Clorinda Matto de Turner trató de abrir los ojos del público sobre la situación de los indígenas de los Andes peruanos con su novela Aves sin nido, una narración que desde mi punto de vista es esencialmente feminista. Siguiendo su ejemplo, en el presente ensayo empleo una estrategia feminista con el propósito de deconstruir su novela del siglo xIX y otras dos que pertenecen al siglo xx, tomando en cuenta cuestiones de género, nación, etnicidad y naturaleza. Las novelas que analizaré además de Aves sin nido son Los ríos profundos de José María Arguedas y La casa verde de Mario Vargas Llosa.

Estas tres obras retratan la vida de los indígenas peruanos en el ámbito social que Pratt denomina la zona de contacto, ${ }^{1}$ donde la epistemología nativa choca con la de los criollos que controlan la sociedad. Este choque de culturas en las tres narraciones ilustra una bipolaridad fundamental: el sistema de valores europeo o europeizado frente al de los indígenas. Los dos epistemes sociales parecieran ser mutuamente exclusivos, o tal vez sería más preciso decir que la cosmovisión socialmente dominante excluye la posibilidad de la existencia de una cosmovisión indígena. Sin embargo, cuando dos conceptos son considerados polos opuestos, por definición se establece una relación entre ellos, un continuo a lo largo del cual se puede recorrer para alcanzar el final de ambos polos opuestos. Dicho continuo, por supuesto, implica estados intermedios o la oportunidad para la fusión de posturas en el terreno medio. El continuo que relaciona a los criollos y a los indígenas en estas tres novelas es, según las palabras de Rodríguez, el "plano dialógico entre patrón y subalternos” (5); en otras palabras, los diversos estratos de la relación entre las fuerzas hegemónicas y contendientes que funcionan en la sociedad.

En el presente trabajo demostraré la manera en que los tres autores emplean elementos de género -tanto abierta como disimuladamente- para representar los papeles sociales tradicionales de las mujeres, los indígenas y los hombres blancos (criollos²) y las

\footnotetext{
${ }^{1}$ Pratt define las zonas de contacto como "social spaces where disparate cultures meet, clash, and grapple with each other, often in highly asymmetrical relations of domination and subordination" (4).

${ }^{2}$ Utilizo los términos "criollo" y "europeizado" para referirme específicamente a los nacidos en Latinoamérica, descendientes de los europeos inmigrantes (por ejemplo, los colonizadores españoles), quienes tradicionalmente constituyen el sector hegemónico de la sociedad. Aunque puede ser que
} 
implicaciones que estos poseen para tratar cuestiones de poder social e individual. Además, explicaré cómo el uso del papel estereotípico de las mujeres y los indígenas se entrelaza con y afecta a la (re)presentación de la naturaleza, la etnicidad y la nación. Ninguna de las líneas que marcan estas categorías son rectas, sino que a menudo se cruzan y se vuelven a cruzar, tal como voy a demostrar a lo largo del presente trabajo. Dicho entrelazamiento o resultado circular en sí mismo tiene más concordancia con el episteme feminista que con la perspectiva binaria que se puede percibir en la inmensa gama de críticas y literaturas canónicas que sirven de material de consulta hasta la actualidad.

Antes de empezar con el análisis, es importante entender el contexto social de términos tales como femenino, masculino y Otro. Típicamente, se juzga a la gente y a los objetos como femeninos si estos manifiestan comportamientos o actitudes de desamparo, frivolidad/insensatez ("haciéndose el tonto"), debilidad física o emocional tales como el llanto, la pasividad u otros atributos considerados infantiles. Otro aspecto más maduro de la femineidad tiene que ver con las responsabilidades domésticas del hogar, el denominado “microespacio": la actitud protectora hacia los niños y jóvenes, el acto de criar (de aquí, la madre tierra), lo tierno, el lado emocional del amor, el acto de disculpar o cualquier emoción "suave” de otra índole que connota características vulnerables. En resumen, se puede decir que todos los rostros de la femineidad se caracterizan por su vulnerabilidad.

Asimismo, se puede definir lo masculino en contraste con lo femenino, su Otro binario. Partiendo de este punto, se percibe a la masculinidad como el opuesto de las características anteriormente mencionadas: físicamente fuerte y emocionalmente inflexible, racional y lógico, un serio defensor de la nación (el macroespacio, fuera del limitado marco del hogar). Esta última característica muy a menudo conduce al conflicto y a la violencia, algo que no se asocia fácilmente con los paradigmas de la femineidad. El hombre masculino está a favor del progreso y la civilización/modernización, y toma medidas para asegurar estos resultados. En resumen, el agente masculino desempeña una función activa en el mundo, sin tener que aguardar pasivamente en el hogar.

Los atributos mencionados líneas arriba detallan las diferencias no entre los sexos biológicamente determinados, sino entre los sexos socialmente definidos, o sea: los géneros. De hecho, tal como Mallón sostiene, “the category of gender [is] understood as the social construction of sexual difference and its use in the organization of power relations” (xix). Cubit y Greenslade concuerdan con esta definición al decir que "[t]he mapping of gender around masculine and feminine polarities onto social relations has created a set of distinctions which associates politics and masculinity with the public world and women with the private, nonpolitical, domestic realm” (53). Dado que el enfoque del presente estudio es justamente la identificación de las formas y del uso del poder por parte de hombres y mujeres, estas definiciones sirven para fundar mis propósitos de deconstrucción de los papeles masculinos y femeninos en las tres obras bajo estudio.

en algún momento este término haya tenido connotaciones de pureza racial, ha habido mucho mestizaje, tanto reconocido como no reconocido, a lo largo de la historia de Latinoamérica hasta tal punto que dicho término actualmente contiene connotaciones de poder social y político más que de raza propiamente dicha. Esencialmente, los criollos son los que controlan el acceso al poder en la sociedad peruana en su conjunto. 
Smith describe la formación de la categoría social del Otro, el cual parte de la distinción entre los géneros. Enfatiza la naturaleza binaria del patriarcado europeo/ europeizado, el cual otorga a los hombres hegemónicos el poder de definir la sociedad y decidir el destino de sus miembros. Dicho patriarcado sitúa a los miembros de la clase hegemónica (los hombres blancos) firmemente en lo alto del continuo binario -definido como el yo de su perspectiva cultural-y a las mujeres en el lado opuesto más bajo que constituye la categoría de alteridad, o el Otro (137). En tiempos coloniales, a medida que las naciones europeas continuaban construyendo sus imperios, también seguían encontrándose con nuevos grupos que no encajaban en las definiciones de su yo. Por consiguiente, estos grupos se convirtieron en Otro al igual que las mujeres; y en vista de que no contaban con una posición central, no se les permitía tener ni voz ni poder.

Debido a esta multiplicidad de grupos feminizados y convertidos en subalternos, considero que la práctica patriarcal de marginar al Otro podría ser apropiadamente representada mediante una rueda con muchos rayos, antes que simplemente como una línea entre dos puntos. El agente masculino europeo/europeizado de clase alta se ubica en el centro de la rueda, o digamos en el centro de su mundo, mientras que todos los agentes subalternos se encuentran al final de los rayos. Alguien que no encaja en la estrecha definición hegemónica del yo es colocado en una de las categorías de lo opuesto, imprecisas y a veces incompletamente definidas (y por lo tanto desconocidas). Sin embargo, existen diversos grados de percepción de la Otredad: por ejemplo, las mujeres son Otras por diferentes razones por las que lo son los indígenas y los negros. Todos los grupos subalternos no encajan bien dentro de una sola categoría que corre linealmente opuesta a la del yo de la hegemonía. Por consiguiente, la metáfora de la rueda que ayuda a ilustrar las distinciones entre estos grupos refleja la "realidad” de un modo más leal que simplemente una línea.

El elemento que permanece igual sin pensar para nada en el grado de Otredad, es el hecho de que ser Otro equivalga a ser inferior. "Soy blanco, él/ella no lo es; él/ella es diferente (Otro) a mí, de modo que por definición, debe ser inferior a mí”. Este es el raciocinio que proporciona justificación para la explotación, objetivización y opresión que crea el contexto para marginar a las identidades en la epistemología imperialista en su conjunto. Además, uno puede notar en esta corriente de razonamiento que la diferencia se define por la falta o la ausencia (San Juan 83-4): él/ella es visto como no blanco/a o no de la clase alta o no cualquier característica que pueda definir al yo. Esto niega cualquier rasgo positivo (aunque diferente) que el Otro pueda ostentar y se enfoca solamente en lo nulo. Dicha manera de ver el mundo puede causar la borradura o invisibilidad o incluso hasta cierto grado la deshumanización: si se define al Otro de acuerdo a las características nulas, se convierte también en nulo en sí mismo, fácil de ignorar, o peor aún fácil de catalogar como algo inhumano y, en consecuencia, disponible para ser utilizado en beneficio de la persona o del grupo que realiza tal definición.

La casa verde, la novela de Vargas Llosa, pinta dicho cuadro de los indígenas como si fueran seres casi inhumanos. Según este autor, la gente nativa no comprende la función de la tecnología o la sociedad "civilizada” y, por lo tanto, es incompetente para competir en el mundo moderno. Vargas Llosa presenta un discurso político que es moderno/ nacionalista/colonialista y que, por lo tanto, constituye un discurso eminentemente 
masculino. Es masculino porque los proyectos de modernización, colonización y formación de la nación tradicionalmente han sido dominados por los hombres, quienes detentan el coraje, la fuerza, la agresividad y la habilidad para funcionar en el macroespacio, el "gran mundo”, más allá de los límites del hogar. El discurso es moderno en el sentido de que presenta al “progreso” y la “civilización” como las fuerzas conductoras de la sociedad. Es colonialista y nacionalista dado que narra la reconquista del Nuevo Mundo, una búsqueda constante de nuevas fronteras, tanto ideológicas como geográficas, para incorporar en la nación. En el siglo xx así como en el siglo xvI, los agentes de cambio influenciados por los europeos -o sea, los criollos y los mestizos europeos/europeizados que buscan ser como ellos- intentan dominar un nuevo territorio.

Por ejemplo, las monjas criollas de La casa verde raptaban a niñas indígenas para criarlas como cristianas en las misiones de la frontera "para ganar unas almas a Dios" (103). Tal tarea no era menos que un intento de aumentar la población del Estado. La gente que vivía en la misión libraba también una constante batalla con la naturaleza, tratando de imponer su voluntad en la selva, acortándola para pasar los límites del dominio civilizado del recinto de la misión. Sin lugar a dudas, dicha gente de tan fuerte voluntad ha logrado su derecho de ser el amo de su medio ambiente.

Contrariamente a esto, Vargas Llosa también ilustra el paradigma indígena y, tal como se puede deducir de sus descripciones, esa gente tan bárbara realmente no tiene la capacidad de competir exitosamente en esta nueva y moderna nación que viene siendo matizada por los criollos. Los indígenas no se visten con ropas apropiadas y siempre andan con los pies descalzos; no tienen concepto de los buenos modales en la mesa, porque comen con las manos y mastican los alimentos ruidosamente; se despiojan el uno al otro como si fueran monos y aplastan los piojos con los dientes; no realizan ningún esfuerzo para abrirse camino en el territorio físico de la selva que pueden llamar el suyo propio. Debido a esta evidente falta de sofisticación, Vargas Llosa parece decir que sería mejor que los indígenas aceptaran la ayuda de la sociedad criolla para mejorar sus vidas. O sea, su conversión religiosa y asimilación a la cultura dominante serían las mejores alternativas para su propio bienestar.

De hecho, la conversión y transculturación de los indígenas son necesarias para los propósitos nacionalistas y homogeneizadores de la hegemonía. En algún nivel quizás subconsciente, reconocen el fundamento originario de la cultura indígena en la formación de su nueva nación moderna y progresista. Sin embargo, al mismo tiempo sienten la necesidad de negar esa fundación, por sus raíces bárbaras y poco civilizadas:

[The nation is founded] by alienating, domesticating, and eventually transculturating that nation's originary barbarism. [...] [T] he task of transculturation is double: one must translate both the European source and the untamed vigor of the nation's barbaric essence. [...] In other words, the civilizing transculturation carried out by the letrado is imperative because barbarism has proven able to disguise itself in the garbs of civilization, beat civilization, as it were, on its own terms. (Avelar 1-2)

Esta perspectiva homogeneizadora y posesiva no es evidente del mismo modo ni en Los ríos profundos ni en Aves sin nido. En verdad, Marcela, la protagonista indígena de Aves sin nido, comprueba muy bien las últimas palabras citadas de Avelar. Tal como 
demostraré líneas abajo, Marcela ha aprendido a disfrazarse con ropa de la civilización y ganarle a la civilización en su propio juego. Por otra parte, en el sentido que nos pinta el cuadro de la vida desde el punto de vista de los indígenas, se puede ver la posesividad del socio hegemónico hacia los subalternos y el medio ambiente. Sin embargo, no se representa como el único modo de vida aceptable, así como lo hace la narración de Vargas Llosa, donde examina el sujeto natural desde la perspectiva criolla menospreciando a los indígenas. Tanto Arguedas como Matto de Turner utilizan un paradigma que muestra la misma sociedad desde la perspectiva del subalterno mirando hacia arriba. En consecuencia, sus discursos se orientan más a favor de la perspectiva indígena.

Por ejemplo, Arguedas define su perspectiva pro-indígena presentando la historia a través de los ojos de un joven criollo, Ernesto, quien fue criado por los sirvientes quechuas de su madrastra. Como resultado de esta crianza, el joven tiene un conocimiento único y muy personal de ambos modos de vida, tanto del criollo como del indígena. Este fenómeno puede ser mejor explicado mediante la discusión de Foucault, quien establece las diferencias entre dos maneras de "saber": savoir (saber) y connaissance (conocer). De acuerdo a Foucault, connaissance es el tipo de conocimiento que se suma al número total de cosas racionalmente conocidas, el número de hechos y datos que se mantiene en la cabeza. Por otra parte, savoir es el conocimiento que efectúa un cambio esencial en el individuo. No es simplemente que uno sepa más detalles y datos, sino que ese detalle del conocimiento de alguna manera causa impacto en la vida y cambia algo de lo que es esa persona. Es este tipo de conocimiento, el savoir, que Ernesto posee de la gente nativa de las comunidades indígenas en las que ha vivido. Sabe a nivel racional que pertenece física y fisiológicamente a la sociedad dominante (connaissance). Sin embargo, siente en lo más profundo de su alma que espiritual y metafísicamente es un miembro del socio nativo (savoir). Este conflicto entre quién es y quién pretende ser nos proporciona la base para el imprevisto giro subalterno sobre la perspectiva privilegiada.

Por su parte, Matto de Turner tiene éxito al combinar lo privilegiado y lo subalterno para presentar un discurso pro-indigenista, asociando a un personaje subalterno femenino, Marcela, con otro privilegiado, Lucía. Su texto muestra su conocimiento de las similitudes y diferencias del estatus de las mujeres criollas e indígenas. Mientras que la criolla, Lucía, es socialmente privilegiada simplemente debido al color de su piel y el dinero que posee su esposo, todavía es subordinada a los hombres por el hecho de ser mujer. A pesar de su estatus social más alto, puede empatizar hasta cierto punto con la posición de la mujer indígena. Matto de Turner saca partido de esta realidad social para crear un personaje criollo quien fusiona lo hegemónico y lo contencioso en un solo cuerpo, y luego combina a este sujeto privilegiado todavía subalterno con un personaje completamente subordinado: Marcela, la indígena. Estas dos mujeres se unen con la intención de confrontar la dinámica de poder de la comunidad dominada por los hombres, con el propósito de proteger a la familia de Marcela para que no la alejen de ella. La narración de Matto de Turner es más proactiva que la de Arguedas, ya que el personaje Ernesto de Los ríos profundos simplemente se sienta al lado y observa el paso del mundo. Marcela y Lucía de Aves sin nido intentan tomar acción para protegerse a sí mismas y a sus seres queridos.

Obviamente, se puede decir que Aves sin nido pertenece tanto al discurso feminista como al indigenista. Matto de Turner en efecto busca despertar la conciencia del público 
lector respecto a la insostenible posición de los indígenas en la sociedad peruana; al mismo tiempo, pone fuerte énfasis en la situación igualmente oprimida de las mujeres. Por supuesto que su enfoque principal se basa en la falta de estatus de la mujer indígena, pero también hasta cierto grado ilustra la objetivización y el menosprecio de la mujer criolla. Este hecho se advierte en instancias cuando el esposo de Lucía se burla y se dirige a ella indulgentemente como si le estuviera hablando a una niña. Matto de Turner narra esas imágenes estereotípicas del "lugar de la mujer” con la finalidad de poder contrarrestarlas, mediante la creación de protagonistas femeninos con mucha fuerza de voluntad, quienes saben utilizar sus mentes y buscar soluciones creativas a los problemas aparentemente insuperables. Matto de Turner también provee protagonistas masculinos compasivos tales como don Fernando, el esposo de Lucía. De este modo, efectivamente evita la trampa de la polaridad patriarcal tradicional de “nosotros contra ellos” o “niños contra niñas”. En esencia, establece el escenario de la toma del poder -hasta el limitado grado posible en esa época-para sus protagonistas femeninas. Este discurso feminista era aun más raro porque fue producido antes del fin del siglo xIx (fue publicado en 1889) en Latinoamérica, en una etapa en la que muchas mujeres no tenían libertad para dar a conocer sus puntos de vista sobre cualquier tema inocuo, ni pensar en asuntos controvertidos tales como los derechos de las clases subalternas.

FEMineidad

Se dice a menudo que la belleza yace en los ojos del observador. En gran medida, el significado es igualmente subjetivo. Lo que vemos, lo que escuchamos, lo que experimentamos pasa a través de nuestro filtro personal. Aunque este hecho no afecte la presente denotación -el "signified” o "fact” según el pensamiento de Foucault- de una experiencia, ciertamente influencia las connotaciones, el "signifier" o la "fiction" de la "truth/reality" percibida por uno (Foucault 36). Para la mayoría del mundo occidental, los filtros de percepción están coloreados por la perspectiva imperialista/colonialista que vengo discutiendo a través de esta investigación, la cual coloca a las mujeres y a los que no son blancos en una posición de alteridad.

Tal como manifesté anteriormente, el término “femenino” no se aplica tan solo a las mujeres, sino que puede aplicarse también a cualquier grupo marginado. Esta definición se puede examinar partiendo del proceso del desempoderamiento psicológico de los indígenas peruanos, ${ }^{3}$ lo cual al fin y al cabo condujo a la alteridad y feminización de su cultura. Asimismo, también mencioné que el término "femenino" tiende a tener una connotación negativa que indica debilidad o desamparo y, la limitación social/geográfica a la casa y la familia. Rodríguez ilustra ambos puntos: la distinción entre "mujer" y "femenino" y la negativa connotación de la femineidad. Enfatiza la fisicalidad concreta (la subjetividad de "la mujer misma encarnada”) y la metafisicalidad abstracta (la objetivización de la femineidad) cuando afirma que "lo femenino sigue siendo objeto de ironía y de descalificación y metáfora del deseo... lo femenino se expresa como deseo/pavor, miedo en el hombre a su propia feminización. Sensibilizarse está ligado a la impotencia; esto es,

\footnotetext{
${ }^{3}$ Véase Fishman 89-90 para una discusión del desarrollo del poder psicológico.
} 
a su pérdida del poder” (30). Rodríguez enfatiza que a ojos del hombre, ser “femenina” es sinónimo de ser impotente y sin poder, estado al que han llegado los indígenas peruanos en la sociedad en su conjunto.

Ésta es la misma connotación de femineidad y feminización que se presenta en varios niveles tanto en Los ríos profundos como en La casa verde. Las mujeres y los indígenas son representados esencialmente como pasivos y sin poder. Sin embargo, estas dos novelas enfocan la feminización desde perspectivas muy diferentes y estas aproximaciones hacen mucha diferencia en la impresión de la sociedad peruana que el lector despreocupado captaría leyendo solamente una u otra de las narraciones. De Los ríos profundos se recibe la impresión de un pueblo subyugado, pero que no obstante merece compasión y respeto. Por el contrario, La casa verde dibuja un cuadro del indígena como bárbaro e incivilizado, persuadiendo al lector a formarse una opinión menos benévola sobre ellos.

Luego, en ambos casos, los indígenas son aun presentados como un grupo sin poder, a veces simples, y claramente feminizados. La diferencia entre Arguedas y Vargas Llosa radica en el hecho de que Arguedas no le pone el juicio de valor a esta condición. Arguedas puede retratarlos como seres feminizados en relación a la sociedad dominante, al igual que Vargas Llosa, pero según el paradigma de Arguedas, esto no es un argumento automático para la aculturación y el desvanecimiento de su identidad indígena.

Asimismo, Arguedas muestra una conexión más patente entre las interacciones de los dos grupos sociales y el estado feminizado de los indígenas, de modo que el lector pueda captar por qué los indígenas se habrían convertido en tan pasivos como lo son. Un botón de muestra es la narración de Arguedas del trato cruel a un pongo nativo por parte de su amo criollo y el desamparo resultante que el narrador ve en los ojos del pongo (18-23). Construye una imagen, no de una cultura eminentemente femenina, sino de una socialmente feminizada. Si los indígenas son personas pasivas y aparentemente dominadas, es porque física y psicológicamente han padecido el látigo de la sumisión durante siglos de contacto con los criollos, amoldados por el proceso hegemónico descrito por Fishman (89-90).

En general, las obras de Arguedas y Vargas Llosa parecen compartir la opinión de una sociedad indígena que es subalterna en relación a la hegemonía, en la que la gente es aparentemente impotente, a veces infantil, emocionalmente débil y limitada única y exclusivamente al microespacio. En cualquiera de las instancias en la que el agente femenino/feminizado muestra signos de agencia personal o poder, tienden a ser episodios aislados lejos del fundamento central de las narraciones. No obstante, queda claro que dichos episodios ocurren y después de haber enfatizado fuertemente la objetivización femenina, quisiera señalar que la "femineidad" no debe constituir una herramienta del patriarcado para mantener al subalterno en su lugar, a pesar de ser típicamente utilizada de una manera paternalista que tiende a minimizar al objeto de dicha feminización. Todo lo contrario, cualquier individuo puede poseer atributos femeninos sin llegar a convertirse en una entidad marginada y dichos atributos pueden ser empleados en beneficio del poseedor.

Matto de Turner ejemplifica este hecho en algunos de los personajes de su novela. Muchos de sus personajes masculinos exhiben ternura y una actitud protectora, rasgos considerados, por supuesto, femeninos. Dos de ellos -uno, indígena; otro, uno de los notables del pueblo- han llegado hasta el punto de dar sus apellidos a los hijos ilegítimos 
de sus esposas, lo cual constituye un caso de aceptación del status quo al cual ellos no tenían que someterse. Después de todo, los hombres no estaban obligados a aceptar en absoluto a hijos ilegítimos, ni mucho menos a darles sus apellidos.

Otro caso es la relación de don Fernando y Lucía, una pareja que recientemente se mudó de Lima. Don Fernando solicita las sugerencias de su esposa; ellos se hablan el uno al otro como si fueran más o menos iguales; Lucía se siente libre para realizar planes y llevarlos a cabo independientemente de su esposo. Debido a esta relativa independencia, puede ayudar a Marcela. Además de estos personajes, la mayoría de los demás protagonistas son mujeres que gozan de cierto grado de poder personal, que pueden hacer sentir sus voces y, que poseen suficiente conocimiento para hacer uso de ellas a fin de lograr un mejor resultado.

Un destacado ejemplo en Los ríos profundos, es cuando las mujeres del pueblo roban sal sin refinar de un almacén local para distribuirla a los pongos, los indígenas esclavos de los latifundios. Este acto constituyó un desafío deliberado contra las autoridades locales que ilustra el beneficio inesperado de ser mujer. Aunque las mujeres no intentaron esconder en absoluto su propósito, las autoridades hicieron la vista gorda y oídos sordos durante la realización del flagrante delito. Aparentemente, dichas autoridades temían las represalias sociales que podían resultar del ataque a una mujer. Este temor era suficiente para prevenirles de tomar medidas contra las mujeres. En vez de arrestarlas públicamente mientras marchaban por el pueblo portando la sal, los policías las apresaron más tarde en sus propios domicilios, después de que todo el tumulto y el desorden habían desaparecido.

Otro ejemplo proviene de La casa verde. Resulta que el fundador de un prostíbulo local había estado viviendo con una niña ciega y muda, y ella perdió la vida al momento de dar a luz a su hijo. Cuando las mujeres de un barrio indígena descubrieron todo esto, se sublevaron y prendieron fuego al prostíbulo. En ambos casos, tanto en Los ríos profundos como en La casa verde, las mujeres ponen sobre el tapete las vidas privadas de ciertos individuos con la finalidad de despertar la conciencia pública y, muestran un ejemplo de esta situación para que se entere el resto del mundo. Lamentablemente, este hecho tiene poca duración porque la historia de los respectivos discursos de subyugación y feminización sigue su curso.

Para mí tiene hondo significado el hecho de que en estas dos obras quienes causan las revoluciones sociales sean las mujeres indígenas y no los hombres. No sólo son ciudadanas de segunda clase debido a su condición indígena, sino que son también mujeres, que se mantienen supuestamente subordinadas a los hombres de cualquier clase social. A pesar de todo, tanto Arguedas como Vargas Llosa muestran ejemplos del grupo más marginado invirtiendo los paradigmas y, por ende, apropiándose del poder en una tentativa de mejorar su situación. Aunque dichos ejemplos son infrecuentes en Los ríos profundos y La casa verde, su mera presencia pareciera indicar al menos un reconocimiento inconsciente de la fortaleza emocional y moral de que son capaces las mujeres de cualquier estrato social.

Sin lugar a dudas, dichos ejemplos de actividad feminista son mucho más frecuentes y deliberados en Aves sin nido que en La casa verde o Los ríos profundos. No sólo los personajes de la novela de Matto de Turner funcionan al estilo feminista. La trama en sí sigue un curso de preocupaciones femeninas y actitudes feministas. No es un simple 
discurso de subyugación por parte de los criollos y la aceptación pasiva por parte de las mujeres y los indígenas. Por el contrario, la autora establece algunas relaciones interesantes entre criollo e indígena, hombre y mujer. A lo largo y ancho de la novela, pinta la estructura del poder del hombre como una típica construcción asimétrica en que dicho individuo controla el macroespacio del mundo entero y las mujeres son relegadas al microespacio del hogar. Al mismo tiempo, describe a varias mujeres, tanto criollas como indígenas, quienes han aprendido la manera como funciona la estructura del poder y a manipularlo para su propio beneficio. Matto de Turner no intenta realmente invertir el sitio del poder, sino simplemente subvertirlo. El objetivo de las mujeres no es echar abajo al hombre e invertir la dinámica de poder, sino obtener justicia de ellos dentro del status quo.

Tal como se señaló previamente, la premisa básica gira alrededor de las intenciones por parte de la mujer indígena de proteger a su familia y mantenerla unida. Fundamentalmente, la trama toma lugar en el microespacio del hogar destinado a las mujeres. Matto de Turner, mediante el empleo de este fundamento femenino en su narrativa, se apodera de la voz privada de esta específica madre marginada y la convierte en pública: aunque Marcela se preocupa solamente de su propia familia, su voz de protesta revela una condición común a la experiencia nativa y, de esta manera, representa a la madre universal.

Jean Franco explica este concepto en su artículo "Going Public: Reinhabiting the Private", donde discute el empoderamiento que resulta de la apertura del microespacio a la vista pública. Cita como ejemplo el impacto causado a la conciencia social por la situación de los desaparecidos de Buenos Aires por parte de las madres de la Plaza de Mayo. Estas madres, abuelas, hermanas y otros parientes femeninos de los desaparecidos marchan todas las semanas en la Plaza de Mayo portando pancartas que exhiben fotografías ampliadas al tamaño de un póster de sus familiares desaparecidos durante la "guerra sucia”. Al revelar la vida privada de su familia para la inspección pública, buscan la concientización del público, dan a conocer su privacidad en el macroespacio y la manera como ésta fue flagrantemente violada. Al volver a establecer sus vidas privadas en el sector público, logran tener voz nuevamente. En otras palabras, por medio de este acto público sobre la vida privada, logran hacerse del poder. Matto de Turner trata de obtener este mismo tipo de atribución de poder para los nativos indígenas fomentando el diálogo sobre las condiciones de su microespacio.

Al desplegar este esfuerzo, Matto de Turner quería manejar "from within but against the grain” (Spivak 13) la situación de la ideología nacionalista de progreso y civilización para la clase elitista de una sociedad desarrollada. Rodríguez apunta este contraste entre el poderoso y el subyugado en su discusión del amo y el subalterno. Yuxtapone el progreso y la civilización de los criollos, en forma de leyes codificadas, con las tradiciones orales y costumbres no escritas de los aborígenes étnicos (5). Su implicación es clara: desde la perspectiva hegemónica, las leyes codificadas y las palabras puestas por escrito son mucho más civilizadas y, por consiguiente, mucho más avanzadas que las simples tradiciones orales. En esta interpretación, la etnicidad nativa, una vez más, llega a ser devaluada o feminizada. De acuerdo con la epistemología dominante, si las leyes no se concretan mediante la escritura, los hombres serán considerados poco más que bárbaros. 
Matto de Turner saca partido en triple sentido de la concepción de nación y subvierte este concepto de “civilización desarrollada”. En primer lugar, su protagonista étnica supuestamente bárbara, Marcela, reconoce el valor de aliarse de algún modo con la clase hegemónica y escoge como su enlace a Lucía, la criolla recientemente llegada de Lima. Por lo tanto, a través de Lucía, coopta las leyes codificadas de progreso y civilización de la élite para su propio beneficio. En este sentido, realiza una autoetnografía, concepto bosquejado por Pratt. La autoetnografía es un proceso que implica (re)apropiarse de los paradigmas de la clase dominante para beneficio propio (7). En el caso de Marcela, en contra del preconcepto que los notables tienen de ella, (re)define su propia existencia como la de una persona con voz, la cual levanta en su propia defensa utilizando las "palabras" -los paradigmas sociales, a los que ha accedido mediante su alianza con Lucía- de la élite gobernante.

En segundo lugar, además de la (re)apropiación de la protagonista del concepto europeo de "nación”, la narradora realiza lo mismo, dándole un giro étnico al significado imperialista de este término. Una noción más apropiada de "nación” que parte del trasfondo del paradigma indígena andino se centra en el concepto de "familia/comunidad" (ayllu). En realidad, Brennan nos recuerda el significado de "nación” que existía antes de la concepción moderna de la nación. ${ }^{4}$ Por su parte, recurre a la raíz latina de la palabra al definir nation como "a local community, domicile, family, condition of belonging” (45). Los términos “nación” y "nativo” derivan de la misma raíz. En consecuencia, en tiempos remotos, la unidad familiar constituía la nación, un concepto muy diferente de la construcción contemporánea de la hegemonía occidental. Por consiguiente, al dar detalles de esta familia indígena, la narradora vuelve a escribir un discurso nacional desde una perspectiva local y en dicho proceso, realiza, según Pratt, "the dynamics of selfrepresentation in the context of colonial subordination and resistance” (5).

En la (re)apropiación final de la definición de "civilización avanzada" son los antagonistas quienes terminan por distorsionarla. Los notables del pueblo-los funcionarios locales de alto rango y el párroco- son supuestamente miembros de la clase hegemónica, aunque no son representantes de Lima, el vector "altamente civilizado”. Estos hombres nacieron y se criaron en este pequeño pueblo andino y están muy ligados a sus tradiciones y privilegios, los que resultaron en la subyugación de la población indígena y el incremento de su propia riqueza. Ahora bien, uno de los artículos que Rodríguez registra bajo la categoría de barbarismo es avaricia, "en el sentido de dinero que no produce capital” (6). En el proceso de incrementar su propia riqueza, estos notables “civilizados” necesariamente no generan capital, y de este modo se sitúan en la categoría que Rodríguez denomina “bárbaro”. Esta dicotomía de “civilizado” y “bárbaro” establece una contradicción social de la cual los notables no tienen conocimiento alguno: en su calidad de supuestos agentes de progreso y civilización, deberían preocuparse más por defender las leyes escritas y producir capital, antes que por sus propias tradiciones locales y riqueza personal. Esta inversión de la dicotomía europea/europeizada de civilización versus barbarie ridiculiza sus supuestos prestigios y refinamientos. Invierte los papeles tradicionales, haciendo que

\footnotetext{
${ }^{4}$ No utilizo el término Estado-nación a propósito, y sigo las definiciones de nación y Estado proporcionadas por Connor (24-26).
} 
los indígenas aparezcan como más “civilizados”, y los mestizos y criollos aculturados como los bárbaros, los subalternos feminizados.

En estas tres narrativas, los personajes femeninos e indígenas no son los únicos que manifiestan femineidad y feminismo. Su etnicidad así como sus alrededores físicos, la naturaleza de la cual dependen profundamente para su propia autoidentificación, poseen también muchos rasgos femeninos. La etnicidad está íntimamente ligada con el mundo natural del texto, ya sea a través de las descripciones comparativas o los detalles del modo de vida de los indígenas. En Aves sin nido y Los ríos profundos la etnicidad está hecha para aparecer natural y eminentemente aceptable. Estos dos textos presentan la otredad de los indígenas como atributo positivo, como algo singular, pero no como una entidad diferente ("otra”) a los criollos. En otras palabras, Matto de Turner y Arguedas dibujan un cuadro de autorreferencia del socio nativo como un ser con su propio derecho, sin tener que recurrir a comparaciones de alteridad con la sociedad criolla. El conocimiento que tienen los indígenas y su apreciación de los ritmos y movimientos de la tierra, sus rituales para adorar a esos ritmos naturales, así como su apariencia física, la manifestación más obvia de su otredad: todos son aspectos celebrados por Arguedas y Matto de Turner de una manera u otra. Estos dos autores nos proporcionan sus descripciones y comentarios sobre la belleza natural del color de la piel y el modo de vivir del indígena.

Por otro lado, tal como señalé anteriormente, en La casa verde la misma etnicidad toma una característica completamente diferente: Vargas Llosa nos ofrece imágenes de bárbaros harapientos y semidesnudos, que comen sus alimentos con la mano, que viven en el medio de la selva sin contar ni siquiera con una vivienda adecuada. En cuanto a su apariencia física real, describe con términos poco atractivos los rasgos físicos del aborigen. En una instancia, Vargas Llosa describe los pies de una niña indígena utilizando un lenguaje despectivo: "sus pies descalzos, del color de las tablas cobrizas del suelo, yacían juntos: dos animales chatos, policéfalos” (21); su elección del sustantivo “animales” y el adjetivo "policéfalos” (con su implicación de rareza de la naturaleza) podría implicar por metonimia su opinión distorsionada en torno a los indígenas en general.

El carácter singular de la cultura indígena, que Arguedas y Matto de Turner aprecian en sus narraciones y Vargas Llosa parece despreciar en la suya, es por consiguiente lo que la hace femenina/feminizada en el episteme homogeneizante del criollo. Es decir, el hecho de que la manifestación étnica del estilo de vida del indígena sea diferente del modo de vida acostumbrado de los criollos, es motivo suficiente para convertirlo en otro/femenino. Por su parte, al hablar de la naturaleza del enlace emocional del nacionalismo, Conversi señala la omnipresencia pero a la vez la irracionalidad de este odio al otro (9-10).

La naturaleza en sí misma tiene un aspecto femenino tanto en el episteme nativo como en el criollo; la diferencia estriba en la connotación positiva o negativa que cada sociedad coloca en la femineidad. Para los indígenas es la casa, el microespacio que provee comida y refugio para protegerlos y criarlos como lo haría una madre. En realidad, la connotación de la palabra quechua para tierra refleja esta plena asociación con la madre: Mama Pacha, madre tierra. La naturaleza es aceptada tal como es, una realidad insustituible de la vida que no necesita estar completamente domada por manos humanas. Proporciona armonía y equilibrio, tal como se ve reflejado en un pasaje poético de Los ríos profundos: 
Se quedaba a vivir algún tiempo en los pueblos de clima templado... Siempre junto a un río pequeño, sin bosques, con grandes piedras lúcidas y peces menudos. El arrayán, los lambras, el sauce, el eucalipto, el capulí, la tara, son árboles de madera limpia... quien busca sombra se acerca a ellos y reposa bajo un árbol que canta solo, con una voz profunda, en que los cielos, el agua y la tierra se confunden. (29)

Este pasaje claramente muestra la aceptación nativa de las voces de la naturaleza y sus contribuciones a las comodidades y necesidades de la vida cotidiana. Esta actitud refleja la supuesta "pasividad" femenina, la aceptación de las cosas tal como son, como lo opuesto al deseo masculino que consiste en el sojuzgamiento de todo lo que ve. En este sentido, los indígenas han feminizado su propio medio ambiente, pero para ellos este hecho tiene una connotación muy positiva, a diferencia de la negativa que se asocia con la interpretación occidental.

Sin embargo, según la ideología dominante, la naturaleza desempeña un papel muy diferente: el del "mito del poder, de lo desconocido y lo misterioso" (Rodríguez 20), el Otro, tal como las mujeres son para los hombres. Pero a menudo se usa la naturaleza como una metáfora para la construcción de la nación y el poder. Dicha naturaleza provee el espacio físico de la nación y constituye la fuente de su poder, dado que los recursos naturales son los que alimentan la industria y proporcionan la materia prima para la acumulación de riqueza. Entonces, ¿es posible que la naturaleza se convierta en una construcción masculina, ya que es la fuente del poder de la nación? Creo que no. La palabra clave es fuente porque es evidente que la naturaleza nos proporciona nutrición y apoyo, desempeñando una vez más un papel maternal.

Asimismo, en vista de que la relación es de explotación, se coloca a la naturaleza en una posición oprimida, “feminizada”. De acuerdo con el episteme colonialista, el hombre lentamente intenta ocupar y controlar todo lo que se encuentra a su alrededor. Tal como Rodríguez indica: "La posición del sujeto que contempla esta naturaleza [es el resultado de] la visión del que la ve y no la del que la trabaja, o lo que es lo mismo, del que la goza y usufructúa” (15). Dicho de otro modo, la naturaleza es un objeto para ser poseído, como una mujer o un recurso del cual sacar beneficio, pero no necesariamente algo que debería respetarse, tal como aparece implícito en la yuxtaposición de Rodríguez sobre los puntos de vista de los que la perciben (desde una distancia) y de los que la trabajan y, por ende, la "conocen” y realmente la aprecian.

Las dos citas siguientes de La casa verde nos indican la concepción imperialista de la naturaleza: "la Amazonía es como una mujer caliente, no se está quieta” (43); "El sol agonizaba a lo lejos, aleteando entre los árboles como un ave rojiza y el río era una plancha inmóvil metálica” (109). En la primera cita, se puede ver cómo tanto las mujeres como la naturaleza son vistas como objetos para ser poseídos y domados. En la segunda cita, es interesante observar la mezcla de lo natural con lo tecnológico, la tradición con el progreso; se puede notar especialmente que se describe a la naturaleza en términos de progreso/civilización y no a la inversa. Enfatiza la visión tecnocentrista de la sociedad progresista y su negativa de reconocer como sujetos a la naturaleza, a la mujer y al nativo. La naturaleza, tal como el nativo y la mujer, es otro, desconocido; como tal, igual que la mujer y el indígena, requiere homogeneización, domesticación y conquista. 
Sin embargo, a diferencia de la mujer y del indígena, el colonizador nunca será capaz de conquistar la naturaleza porque ésta no posee un inconsciente en el que las fuerzas hegemónicas puedan realizar sus juegos psicológicos. No importa el grado de intensidad con que el hombre empuje, la naturaleza vuelve a empujar con la misma intensidad. Posee un poder inherente que no puede ser completamente domado. Por ejemplo, las tormentas y las inundaciones son imprevisibles y, no importa el grado de mutilación de la jungla, los árboles volverán a crecer e invadir el espacio “civilizado”. En este sentido de fortaleza y persistencia, la naturaleza femenina acepta la masculinidad del discurso hegemónico. Aunque no posee conciencia, puede resistir lo que los vectores subalternos humanos son incapaces de resistir: la manipulación de las manos, el corazón y los ojos posesivos del seeing-man (Pratt 7). Esta es posiblemente la última subversión del discurso masculino para la (re)apropiación del tropo femenino.

\section{MASCULINIDAD}

A lo largo de la presente investigación se han contrapuesto lo femenino y lo masculino, enfatizando así otra manera de interpretar lo femenino en las tres novelas bajo consideración. Del mismo modo, ahora volvemos la atención a lo masculino, buscando así maneras alternativas de interpretar dicho paradigma. Empezamos con el texto de Vargas Llosa, ya que es el más obviamente masculino.

Un elemento que contribuye a la masculinidad total de La casa verde es la perspectiva del narrador. El punto de vista es muy macho, muy dominante, agresivo y colonialista. Incluso las imágenes de la etnicidad ponen fuerte énfasis en el machismo: por ejemplo cuando los indígenas o mestizos (varones) de los barrios pobres adoptan los paradigmas más binarios (superior/inferior, más que nada con respecto a sus mujeres y a los indígenas de otras comunidades) de sus "superiores" sociales, los criollos, aunque ellos nunca abrigan esperanzas de lograr igual estatus. En estos episodios de La casa verde, se presenta al indígena de la ciudad como alguien más aculturado a los modos de vida de los criollos, de manera que aunque es indígena, en esencia es presentado como alguien más “civilizado” en comparación con los “salvajes” del interior de la selva.

Debido a que estos indígenas citadinos han sido absorbidos por la cultura dominante, se puede decir que el colonialismo ha tenido éxito, al menos hasta cierto punto, en lo que a este grupo concierne. Según la terminología de Smith, el sujeto indígena se ha discernido, se ha desheredado de sus raíces ancestrales (xxx). ${ }^{5}$ En este proceso, se ha colocado -o se ha dejado colocar- al indígena rotundamente en el peldaño inferior de la escala social, en un medio en el cual existe poca esperanza para escalar lo mínimo. O quizás no esté completamente condenado a ese estatus inferior: en las tres narraciones que se discutieron en el presente trabajo, se les atribuye a las mujeres una posición separada del

\footnotetext{
${ }^{5}$ En la introducción del libro, Smith habla de “cerning the subject”, o un proceso de abstracción del sujeto: "The word 'cerning' conflates and plays simultaneously upon two rarely used English verbs - 'to cern' and 'to cerne'. The first means 'to accept an inheritance or a patrimony'” (xxx). Por consiguiente, dis-cernir sería negar o rechazar el patrimonio, o tal vez quitárselo a los indígenas urbanizados, según el contexto en que lo empleo en el presente estudio.
} 
hombre, por ejemplo cuando Arguedas ocasionalmente se refiere a "los indios y sus mujeres”. Dicha distinción entre los sexos pareciera indicar un profundo conocimiento de la otredad de las mujeres; por lo menos los criollos y los indígenas aún tienen en común sus cualidades masculinas.

Estos indígenas aculturados en la obra de Vargas Llosa, se identifican todavía con sus raíces étnicas individuales. Varias veces repiten frases tales como “¿No soy mangache?” o “Todos sabemos que los mangaches son los mejores” y otras manifestaciones de orgullo étnico. Sin embargo, incluso dichas actitudes étnicamente orientadas reflejan el episteme nacionalista en tanto que intentan establecer la jerarquía de superioridad/inferioridad, especialmente en relación a los demás grupos étnicos. Por ejemplo, es posible que los mangaches respeten a sus propias mujeres, pero se toman la libertad de acechar a las mujeres gallinazo cuando se les antoja para satisfacer sus apetitos sexuales (123). Con algunas pocas excepciones, en la narrativa de Vargas Llosa las mujeres parecen poseer menos estatus que las comunidades indígenas de la selva.

En realidad, las tres obras exhiben hasta cierto punto asuntos de nación y nacionalismo. Este paradigma refleja claramente la imagen masculina, ya que la construcción de la nación constituye una tentativa de conquista del macroespacio, que requiere mucho valor y fortaleza física. Chatterjee propone la tesis de que mientras el nacionalismo puede originalmente resultar de motivos relativamente puros -"the universal urge for liberty and progress"- no obstante posee la capacidad de cambiar esos nobles objetivos y convertirse en justificación de la "mindless chauvinism and xenophobia [,]... organized violence and tyranny" (2). Ambas direcciones divergentes del nacionalismo son evidentes en Latinoamérica a lo largo de su historia, cuyas direcciones son representadas en el discurso de Vargas Llosa en La casa verde.

Por ejemplo, a las monjas de La casa verde les gustaría reclamar los motivos puros de libertad y progreso de la nación, pero en realidad ellas constituyen simplemente un método más, junto con los militares y las patrullas civiles, para imponer la hegemonía homogeneizante del Estado sobre el socio natural. Está por dado que ellas no han exhibido abiertamente un chauvinismo sin motivo ni violencia. Incluso algunas de las monjas aprendieron a hablar algunas de las lenguas locales y comían las comidas del lugar con el mismo gusto que los nativos. Sin embargo, en vista de que estas monjas tratan de imponer sus creencias a la población indígena e intentan homogeneizar a los indígenas en la cultura criolla, aún todavía representan el aspecto adquisitivo/posesivo del nacionalismo.

El lado negativo del nacionalismo o la construcción de la nación es evidente en los textos bajo consideración a través de la agencia de otra construcción de Pratt, que ella denomina el seeing-man, en su campaña de anticonquista. Propone el término anticonquista para describir el autoengaño de los agentes de la colonización que realmente no conquistan nada ni a nadie. Todos los cambios profundos que dichos agentes se esfuerzan por realizar son supuestamente para el bienestar de los indígenas, de modo que ellos constituyen, en realidad, las fuerzas benéficas del nuevo territorio. Según las propias palabras de Pratt, el seeing-man es "the European male subject of European landscape discourse -he whose imperial eyes passively look out and possess” (7).

En La casa verde, el personaje del sargento Roberto Delgado ejemplifica al seeingman. El sargento y sus soldados tratan de descubrir a alguien que creen que es un criminal 
sin piedad cuando descubren a un pueblo pequeño aparentemente abandonado. El sargento quería ver lo que se encontraba disponible para llevar: “-Vamos a registrar antes que lleguen los otros.... A lo mejor queda algo que valga la pena” (226). Obviamente, este sargento estaba interesado en lo que podía encontrar para sí mismo y no aceptaba la idea de tener que compartir el botín con otros individuos. En un episodio anterior, ni siquiera le preocupaba que el pueblo estuviera realmente abandonado. Aunque no se veía a los nativos en ninguna parte, los hombres del sargento hicieron una incursión en el pueblo con la finalidad de encontrar algo.

Matto de Turner también ilustra la anticonquista de este seeing-man al describir los sistemas de pongos, faenas y mitas: estos fueron esencialmente posiciones de labores forzadas y sin pago para agentes subalternos en las casas y tierras de los privilegiados. Sin embargo, esto no se llevaba a cabo “conquistando" o "subyugando" de acuerdo a los élites dominantes, sino que simplemente significaba la continuación de una tradición provincial existente desde hace mucho tiempo. El pastor de la iglesia local, por ejemplo, aceptaba los servicios -en el amplio sentido de la palabra- de las doncellas del pueblo como el derecho otorgado por Dios, a medida que ellas alcanzaban la madurez sexual y florecía su belleza natural. Esta indiferencia por la calidad de persona de los nativos es en esencia una extensión de la indiferencia del agente europeo hacia la naturaleza en general. La naturaleza es ingobernable. La naturaleza constituye nada más que un recurso para ser domado y explotado, y lo mismo se puede decir de los nativos. Esta actitud es más evidente en $L a$ casa verde que en las otras dos novelas.

Sin embargo, lo que Matto de Turner expresa a través de su discurso, es que ésta no es una ecuación válida. Mientras que ilustra la objetivización, la “feminización” del socio nativo dentro del status quo, simultáneamente niega esa imagen utilizando algunas estrategias sutiles y muchas veces no muy sutiles, tal como acabo de demostrar. Narra la posibilidad de subvertir la estructura del poder laborando dentro del sistema establecido. Arguedas realiza lo mismo, hasta cierto punto, al final de su novela Los ríos profundos, cuando los pongos de los latifundios se levantan en masa para convergir en la ciudad. Sin embargo, ellos hacen esto debido a una epidemia y quieren desesperadamente ser bendecidos por el párroco local. En vista de que su levantamiento es para exigir su inclusión de alguna manera al sistema patriarcal, este acto no puede ser clasificado como una sublevación propiamente dicha. Por el contrario, puede ser visto como un éxito más del sistema, en vista de que los indígenas han sido aculturados hasta el punto de llegar a adorar al Dios de los criollos.

\section{Conclusiones}

En esta investigación he tratado de establecer diferencias entre lo femenino, lo masculino y lo feminista. He examinado tres novelas de autores peruanos que tratan temas indígenas y las he desconstruído a fin de postular una perspectiva feminista sobre cuestiones relacionadas con los papeles de las mujeres y el modo cómo funcionan tanto lo femenino como lo masculino dentro de los paradigmas de etnicidad, nación y el mundo natural. 
Además, en el presente ensayo, he discutido la manera en que el agente hegemónico ha tratado de dominar y controlar su medio ambiente y cómo ha intentado subyugar y feminizar a aquellos que se encontraban en ese espacio. En gran parte, dicho agente hegemónico ha tenido éxito en sofocar la voz del subalterno marginado, tal como puede percibirse claramente en los Los ríos profundos y La casa verde. Pero, al fin y al cabo, tal como Matto de Turner muy elocuentemente lo manifiesta, y Arguedas y Vargas Llosa lo insinúan, siempre ha habido algunos marginados que han rechazado ser silenciados y han encontrado la forma de funcionar dentro del sistema que actualmente existe con la finalidad de hacer que sus voces sean escuchadas. Tal como Kaminsky acertadamente señala: "the disempowered have earned their right to speak, and they have been required, as the powerful have not, to understand the workings of the systems of the powerful in order to survive" (4). En Aves sin nido, los que no ostentan el poder han descubierto métodos de (re)apropiación cultural, cuya apariencia superficial encaja perfectamente dentro de los parámetros de la epistemología dominante, pero cuya utilización por parte de los agentes subalternos desplaza el significado y restaura la voz de la alteridad.

\section{Bibliografía}

Arguedas, José María. Los ríos profundos. Madrid: Alianza, 1994.

Avelar, Idelber. “Transculturation and Nationhood”. <http://www.tulane.edu/ avelar/ transcult.html> Fecha de bajada: 11/21/02. También en The Presence of Amerindian Cultures. Vol. III de Latin American Literatures: A Comparative History of Cultural Formations. Mario Valdés y Linda Hutcheon, eds. 3 vols. Oxford: Oxford University Press, en prensa.

Brennan, Timothy. "The National Longing for Form”. Nation and Narration. Homi K. Bhabha, ed. New York: Routledge, 1990. 44-70.

Chatterjee, Partha. Nationalist Thought and the Colonial World. Minneapolis: University of Minnesota Press, 1993.

Connor, Walker. "Nationalism and Political Illegitimacy". Ethnonationalism in the Contemporary World: Walker Connor and the Study of Nationalism. Daniele Conversi, ed. London: Routledge, 2002. 24-49.

Conversi, Daniele. "Conceptualizing Nationalism: An Introduction to Walker Connor's Work". Ethnonationalism in the Contemporary World: Walker Connor and the Study of Nationalism. Daniele Conversi, ed. London: Routledge, 2002. 1-23.

Cubitt, Tessa \& Helen Greenslade. "Public and Private Spheres: The End of Dichotomy”. Gender Politics in Latin America: Debates in Theory and Practice. Elizabeth Dore, ed. New York: Monthly Review Press, 1997.

Fishman, Pamela. “Interaction: The Work Women Do”. Language, Gender and Society. Annie Thorne, Cheris Kramarae y Nancy Kenley, eds. Rowley: Newbury House, 1983. 89-101.

Foucault, Michel. Remarks on Marx: Conversations with Duccio Trombadori. R. James Goldstein y James Cascaito, trads. New York: Semiotext(e), 1991.

Franco, Jean. "Going Public: Reinhabiting the Private”. On Edge: The Crisis of Contemporary Latin American Culture. George Yúdice, Jean Franco y Juan Flores, eds. Minneapolis: University of Minnesota Press, 1992. 65-83. 
Kaminsky, Amy. Reading the Body Politic: Feminist Criticism and Latin American Women Writers. Minneapolis: University of Minnesota Press, 1993.

Mallón, Florencia E. Peasant and Nation: The Making of Postcolonial México and Peru. Berkeley: University of California Press, 1995.

Matto de Turner, Clorinda. Aves sin nido. Buenos Aires: Solar, 1968.

Pratt, Mary Louise. Imperial Eyes: Travel Writing and Transculturation. London: Routledge, 1992.

Rodríguez, Ileana. Transición: nación, etnia, género: lo masculino. Latin American Studies Center Ser. 4. College Park: University of Maryland, 1992.

San Juan, E., Jr. Beyond Postcolonial Theory. New York: St. Martin’s Press, 1999.

Smith, Paul. Discerning the Subject. Minneapolis: University of Minnesota Press, 1988.

Spivak, Gayatri Chakravorty. "Subaltern Studies: Deconstructing Historiography”. Selected Subaltern Studies. Ranajit Guha y Gayatri Chakravorty Spivak, eds. New York: Oxford University Press, 1988. 3-32.

Vargas Llosa, Mario. La casa verde. Bogotá: Oveja Negra, 1984. 